\title{
STUDY ON HAEMORRHAGE IN 1ST TRIMESTER OF PREGNANCY AND ITS EVALUATION BY TRANSVAGINAL SONOGRAPHY
}

\author{
Punita Kumari ${ }^{1}$, Chitra Sinha ${ }^{2}$, Chander Kiran ${ }^{3}$, Sunita Kumari ${ }^{4}$, Shalini ${ }^{5}$, Arpana Kumari ${ }^{6}$, Supriya Kumari ${ }^{7}$
}

${ }_{1}^{1}$ Postgraduate Student, Department of Obstetrics \& Gynaecology, PMCH, Patna.

${ }^{2}$ Associate Professor, Department of Obstetrics \& Gynaecology, PMCH, Patna.

3Professor \& HOD, Department of Obstetrics \& Gynaecology, PMCH, Patna.

${ }^{4}$ Assistant Professor, Department of Obstetrics \& Gynaecology, PMCH, Patna.

${ }^{5}$ Medical Officer, PMCH, Patna.

${ }^{6}$ Postgraduate Student, Department of Obstetrics \& Gynaecology, PMCH, Patna.

${ }^{7}$ Postgraduate Student, Department of Obstetrics \& Gynaecology, PMCH, Patna.

\section{ABSTRACT}

\section{BACKGROUND}

Vaginal bleeding in the first trimester of pregnancy is a common obstetric problem and causes worry and anxiety both to the patient and the obstetrician. The first twelve weeks of intrauterine life are the most crucial period which needs a careful eye on the growing foetus inside.

The aim of this study is to evaluate the role of Transvaginal Ultrasonography in cases of vaginal bleeding in the first trimester of pregnancy and also to-

1. Identify the cause of vaginal bleeding in first trimester of pregnancy. 2. Confirm the clinical diagnosis. 3. Better Management. 4. Save the life of women in cases acute ectopic pregnancy by early intervention. 5. Spare the patients from unnecessary intervention in cases of complete abortion and threatened abortion.

\section{MATERIALS AND METHODS}

The study was carried out in the Department of Obstetrics and Gynaecology of Patna Medical College Hospital, Patna during the period from October 2014 to September 2016. 100 Pregnant patients presenting with bleeding per vaginum in first trimester of pregnancy were included.

Statistical Method- Chi square method.

Study Design- Descriptive study.

\section{RESULTS}

Abortions contributed to the major cause of first trimester, bleeding constituting $85 \%$, ectopic pregnancy constituting $10 \%$ and molar pregnancy in $5 \%$ cases.

\section{CONCLUSION}

Transvaginal sonography is a gold standard modality for diagnosis of haemorrhage in the first trimester of pregnancy.

\section{KEYWORDS}

TVS, Vaginal Bleeding, Abortion.

HOW TO CITE THIS ARTICLE: Kumari P, Sinha C, Kiran C, et al. Study on haemorrhage in $1^{\text {st }}$ trimester of pregnancy and its evaluation by transvaginal sonography. J. Evolution Med. Dent. Sci. 2017;6(49):3789-3791, DOI: 10.14260/Jemds/2017/819

\section{BACKGROUND}

Vaginal bleeding in the first trimester of pregnancy is a common obstetric problem and causes worry and anxiety both to the patient and the obstetrician. First trimester is a dynamic period which spans ovulation, fertilisation, implantation and organogenesis. $20-25 \%$ of pregnant women will have bleeding of some degree during early months of gestation. The significance of bleeding in early pregnancy in a given patient may range from an inconsequential episode to a life-threatening emergency. ${ }^{1}$

Financial or Other, Competing Interest: None.

Submission 17-04-2017, Peer Review 07-06-2017,

Acceptance 13-06-2017, Published 19-06-2017.

Corresponding Author:

Dr. Punita Kumari,

C/o. Nandu Prasad Khetan,

Janpul Chowk, Near Madhav Talkies,

East Champaran, Motihari-845401, Bihar.

E-mail:drpunita03@gmail.com

DOI: $10.14260 /$ jemds $/ 2017 / 819$

\section{(c) () $\ominus$}

The first twelve weeks of intrauterine life are the most crucial period which needs a careful eye on the growing foetus inside. If bleeding occurs at this stage, history and clinical examination may frequently be inconclusive.

Ultrasound plays a role of utmost importance in confirming the pregnancy, site of pregnancy, viability and also in predicting whether a pregnancy has a good chance of continuing or it is destined to fail or has already failed.

The three major causes of bleeding in first trimester are abortion, ectopic pregnancy and molar pregnancy. Ultrasonography helps in assessing the type of abortion, early diagnosis and better management. It is also useful in followup case of molar pregnancy.

A life-threatening emergency like ectopic when evaluated by ultrasonography gives scope for conservative approach without affecting the fertility status as it is non-invasive and easily accessible and it is a most commonly used diagnostic modality. Real time sonography is a non-invasive modality that is extremely useful to arrive at an accurate diagnosis. 
"Ultrasound has become boon to Obstetrics"

\section{MATERIALS AND METHODS}

This descriptive study was carried out in the Department of Obstetrics and Gynaecology, Patna Medical College Hospital, Patna during the period from October 2014 to September 2016.

\section{Inclusion Criteria}

Cases with bleeding per vaginum in the first trimester of Pregnancy were included.

\section{Exclusion Criteria}

Cases with vaginal bleeding after 12 weeks of pregnancy were excluded.

Detailed history was taken from selected patients- History of amenorrhoea and bleeding per vaginum, Volume, Duration, Intermittent/continuous, History of passing clots; Pain abdomen- Duration, Site and nature of pain, Menstrual history -LMP; Obstetric history -Gravida, parity, Living child and abortion.

\section{Clinical Examination}

- Per abdomen size of uterus, feel of uterus and tenderness.

- Per speculum examination- bleeding, presence of clots.

- Per vaginum examination- uterine size, fornices, cervical os closed/open.

\section{Investigation}

HIV, HBsAg kit, VDRL test, Haemoglobin level, ABO and Rh typing, Blood sugar 2 hours after 75 g glucose, Routine examination of urine, Pregnancy test in some cases, Serum beta HCG in selected patients, Transvaginal ultrasonography.

Transvaginal sonography was done using $8 \mathrm{MHz}$ endovaginal probe fitted in Logiq P3 model ultrasonography machine.

\section{RESULTS}

\begin{tabular}{|c|c|c|}
\hline Clinical Diagnosis & No. of Cases & Percentage \\
\hline Threatened abortion & 32 & 32 \\
\hline Incomplete abortion & 26 & 26 \\
\hline Missed abortion & 16 & 16 \\
\hline Complete abortion & 11 & 11 \\
\hline Ectopic Pregnancy & 10 & 10 \\
\hline Molar Pregnancy & 5 & 5 \\
\hline Total & 100 & 100 \\
\hline \multicolumn{3}{|c|}{$\begin{array}{l}\text { Table 1. Distribution of Cases } \\
\text { According to Clinical Diagnosis }\end{array}$} \\
\hline
\end{tabular}

32 cases $(32 \%)$ were clinically diagnosed as threatened abortion, 26 cases (26\%) as incomplete abortion, 11 cases $(11 \%)$ as complete abortion, 16 cases $(16 \%)$ as missed abortion, 10 cases $(10 \%)$ as ectopic pregnancy and 5 cases (5\%) were diagnosed as molar pregnancy.

\begin{tabular}{|c|c|c|c|c|}
\hline $\begin{array}{c}\text { Sl. } \\
\text { No. }\end{array}$ & $\begin{array}{c}\text { No. of } \\
\text { Cases }\end{array}$ & $\begin{array}{c}\text { Clinical } \\
\text { Diagnosis }\end{array}$ & $\begin{array}{c}\text { USG Diagnosis } \\
\text { by TVS }\end{array}$ & $\begin{array}{c}\text { Correlation of Clinical } \\
\text { Diagnosis \& USG Findings }\end{array}$ \\
\hline 1. & 32 & Threatened abortion & $\begin{array}{c}26 \text { cases - Threatened abortion } \\
3 \text { cases - Missed abortion } \\
2 \text { cases - Blighted ovum } \\
1 \text { case - No RPOC }\end{array}$ & $\begin{array}{c}\text { In 81.25\% cases clinical diagnosis } \\
\text { was confirmed by TVS. }\end{array}$ \\
\hline 2. & 26 & Incomplete abortion & $\begin{array}{c}20 \text { cases - RPOC } \\
6 \text { cases - Empty uterus }\end{array}$ & $\begin{array}{c}\text { Clinical diagnosis was confirmed } \\
\text { in } 77 \% \text { of cases by TVS }\end{array}$ \\
\hline 3. & 16 & Missed abortion & $\begin{array}{c}13 \text { cases - Missed abortion } \\
1 \text { case - Blighted ovum } \\
2 \text { cases - Followup suggested }\end{array}$ & $\begin{array}{c}\text { Clinical diagnosis was confirmed in } 81.25 \% \\
\text { cases \& followup } 12.5 \% \text { cases confirmed as } \\
\text { incomplete abortion by TVS }\end{array}$ \\
\hline 4. & 11 & Complete abortion & $\begin{array}{c}10 \text { cases - Complete abortion } \\
1 \text { case - RPOC }\end{array}$ & $\begin{array}{c}\text { Clinical diagnosis was confirmed } \\
\text { by TVS in } 91 \% \text { cases }\end{array}$ \\
\hline 5. & 10 & Ectopic Pregnancy & $\begin{array}{r}9 \text { cases - Ruptured, ectopic } \\
1 \text { case - Unruptured }\end{array}$ & $\begin{array}{c}\text { In 100\% clinical diagnosis was } \\
\text { confirmed by TVS }\end{array}$ \\
\hline 6. & 5 & Molar Pregnancy & Thowstorm appearance & $100 \%$ cases confirmed by TVS \\
\hline
\end{tabular}

By TVS, $81.25 \%$ cases of threatened abortion, $77 \%$ cases of incomplete abortion, $81.25 \%$ cases of missed abortion, $91 \%$ cases complete abortion, $100 \%$ cases of ectopic pregnancy and $100 \%$ cases of molar pregnancy was confirmed.

In the present study, various types of abortions contributed to the major cause of first trimester bleeding constituting $85 \%$, ectopic pregnancy constituting $10 \%$ and molar pregnancy in $5 \%$ cases. P Reddi Rani et $\mathrm{al}^{2}(2000)$ and Satish k Bhargava et al ${ }^{3}(1988$ ) also noted that abortion is the leading cause of early pregnancy bleeding with an incidence of $61 \%$ and $81.6 \%$ respectively, incidence of ectopic pregnancy $21 \%$ and $13 \%$ respectively and incidence of molar pregnancy $18 \%$ and $4.35 \%$ respectively. Finding of present study is compared with Satish K Bhargava et al 3 (1988) study.

\section{DISCUSSION}

On the basis of symptoms, signs and clinical examination, provisional diagnosis was made. 32 cases were clinically diagnosed as threatened abortion. Out of 32 cases of clinically diagnosed threatened abortion, 26 cases $(81.25 \%$ cases $)$ were confirmed by TVS as threatened abortion, 3 cases $(9.37 \%)$ were diagnosed by TVS as missed abortion, 2 cases (6.26\%) were blighted ovum and in 1 case $(3.12 \%)$ no product of conception was seen. This finding correlated with Dr. Vishwanath et $\mathrm{al}^{4}$ (2015).

In the present study, 26 cases $(26 \%)$ were clinically diagnosed as incomplete abortion. 77\% cases of incomplete abortion were confirmed by TVS. Dr Krishna K Borah et $\mathrm{al}^{5}$ (2016) observed that $100 \%$ patients were diagnosed as incomplete abortion. These cases showed a heterogenous or mixed echogenic mass inside the endometrial cavity with no 
proper foetal configuration, no foetal heart rate was seen inside the mixed echogenic mass. The result of present study is not similar to Dr. Krishna k Borah et al (2016) study.

16 cases were clinically diagnosed as missed abortion, out of that 13 cases $(81.25 \%)$ were confirmed by TVS as missed abortion, 1 case $(6.25 \%)$ was blighted ovum and followup suggested in $2(12.5 \%)$ cases. On followup, the above 2 cases were diagnosed as incomplete abortion. Dr. Krishna k Borah et al (2016) found $80 \%$ of missed abortion in their study group.

11 cases were clinically diagnosed as complete abortion. Product of conception was not seen in 10 cases (91\%) on TVS and 1 case $(9 \%)$ was diagnosed as incomplete abortion. So in 91\% cases, clinical diagnosis was confirmed by TVS and these patients spared from unnecessary intervention. A similar study done by Rulin \& co-workers ${ }^{6}$ (1993) found empty uterus using TVS in 48 out of 49 cases ( $>98 \%$ ). Observation of the present study is almost similar.

10 cases were diagnosed clinically as ectopic pregnancy. On TVS finding, 9 cases (90\%) were confirmed as ruptured ectopic pregnancy and 1 case $(10 \%)$ was confirmed as unruptured ectopic pregnancy. Clinical diagnosis was confirmed by TVS in $100 \%$ cases. Satish K Bhargava et al (1988) also found 13\% cases of ectopic pregnancy in their study group and on ultrasonography almost all cases were confirmed as ectopic pregnancy. P. Reddi Rani et al (2000) observed $21 \%$ cases of ectopic pregnancy in their study. The finding of present study is consistent with finding of Satish $\mathrm{K}$ Bhargava et al (1988) study and not consistent with P. Reddi Rani et al (2000) study.

In the present study, 5 cases were diagnosed clinically as molar pregnancy and on TVS $100 \%$ cases were confirmed. Satish K Bhargava et al (1988) observed 4.35\% cases of molar pregnancy in their study group and P. Reddi Rani et al (2000) found $18 \%$ cases of molar pregnancy. Observation of present study is similar to Satish K Bhargava et al (1988) study.

In 100 cases of present study, 43 cases were managed conservatively on the basis of TVS finding, 47 cases underwent suction \& evacuation and in 10 cases laparotomy was done. Malhotra et $\mathrm{al}^{7}$ (1987) managed 46 cases conservatively as ultrasound showed viable pregnancy, 98 cases by suction \& evacuation and 21 cases by laparotomy. This finding of present study is not in accordance with the finding of Malhotra et al (1987) which may be due to large sample size.

\section{CONCLUSION}

In the present study, 100 cases with haemorrhage in first trimester of pregnancy were evaluated by TVS. Transvaginal sonography is a gold standard modality for diagnosis of haemorrhage in first trimester of pregnancy.

It appears that TVS is a very valuable tool in the diagnosis of various causes of bleeding per vaginum in first trimester of pregnancy. It not only helps in ruling out the dilemma when assessed clinically but also is more accurate, safe, noninvasive and quick in diagnosis and management of such cases. Ultrasonography positively helps in accessing the safe continuation of pregnancy, timely intervention for abnormal pregnancy and avoiding unnecessary intervention in those cases that do not need them. Blighted ovum is diagnosed only by ultrasonography.

\section{REFERENCES}

[1] Paspulati RM, Bhatt S, Nour SG. Sonographic evaluation of first trimester bleeding [published correction appears in Radiol Clin North Am. 2008; 46(2):437]. Radiol Clin North Am.2004;42(2):297314.http://www.sciencedirect.com/science/journal/00 338389.

[2] P. Reddirani, V Sunita, Ultrasound Evaluation of cause of vaginal bleeding in first trimester of pregnancy, J Obstet Gynecol Ind Feb 2000; vol.50,No.1: Pg 54-58.

[3] Ramu Dimri, Satish K Bhargava. Transvaginal sonography in obstetrics and Gynaecology, New Deilhi,India,1988; 44: pg 97-159.

[4] Dr. Vishwanath Yadav, Dr. Santosh, Dr. Bharathi; Ultrasonographic Evaluation and Management of the First Trimester Bleeding; Volume 14, Issue 12 Ver.VI (Dec 2015) PP 43-46.

[5] Dr Krishna Kumar Borah, Dr Pranoy Phulkan, Dr (Mrs) Charusmita Choudhary; Bleeding per vaginum in first trimester of pregnancy role of USG its correlation with clinical assessment ;JMSCR vol-4 issue-2feb 2016 page 9573-9581

[6] Rulin MC, Bornstein SG, Campbell JD: The reliability of ultrasonography in the management of spontaneous abortion thought to be complete: A prospective study, Am J Obstet Gynecol 168:12,1993.

[7] Jaideep Malhotra, K Saxena and N Malhotra. Ultrasound evaluation of first trimester bleeding per vaginum. J Obstetrics \& Gynecology of India, 1987; 37:341-343. 